\title{
MYH-9 Related Platelet Disorders: Strategies for Management and Diagnosis
}

\author{
Karina Althaus Andreas Greinacher \\ Institut für Immunologie und Transfusionsmedizin, Ernst-Moritz-Arndt Universität Greifswald, Germany
}

\section{Keywords}

MYH9 gene · Non-musclular myosin IIA - May-Hegglin anomaly - Epstein syndrome - Fechtner syndrome .

Sebastian platelet syndrome $\cdot$ Macrothrombocytopenia

\section{Summary}

$\mathrm{MYH}-9$ related platelet disorders belong to the group of inherited giant platelet disorders. The $\mathrm{MYH}-9$ gene encodes the non-muscular myosin heavy chain IIA (NMMHCIIA), a cytoskeletal contractile protein. Several mutations in the $M Y H-9$ gene lead to macrothrombocytopenia, and cytoplasmic inclusion bodies within leukocytes, while the number of megakaryocytes in the bone marrow is normal. Four overlapping syndromes, known as May-Hegglin anomaly, Epstein syndrome, Fechtner syndrome and Sebastian platelet syndrome, describe different clinical manifestations of MYH9 gene mutations. Macrothrombocytopenia is present in all affected individuals, whereas only some develop additional clinical manifestations such as renal failure, hearing loss and presenile cataracts. The bleeding tendency is usually moderate, with menorrhagia and easy bruising being most frequent. The biggest risk for the individual is inappropriate treatment due to misdiagnosis of chronic autoimmune thrombocytopenia. More than 30 mutations within the 40 exons of the $M Y H-9$ gene leading to macrothrombocytopenia have been identified, of which the upstream mutations up to amino acid $\sim 1400$ are more likely associated with syndromic manifestations than the downstream mutations. Diagnosis is based on identification of the granulocyte inclusion bodies using blood smears and immunofluorescence and is finally confirmed by identifying the mutation. Treatment is supportive and should be aimed to prevent iron deficiency anemia. Beside renal failure, the biggest risk for patients affected by a MYH-9 disorder are the adverse effects resulting form treatment based on the misdiagnosis of immune thrombocytopenia.

\author{
Schlüsselwörter \\ MYH9-Gen · Nichtmuskuläres Myosin IIA · May-Hegglin- \\ Anomalie - Epstein-Syndrom · Fechtner-Syndrom . \\ Sebastian-Syndrom - Makrothrombozytopenie
}

\section{Zusammenfassung}

MYH-9-bedingte Thrombozytenstörungen gehören zur Gruppe der angeborenen makrothrombozytären Thrombopathien. Das $\mathrm{MYH}-9$-Gen kodiert die schwere Kette des nichtmuskulären Myosins IIA (NMMHC-IIA), eines zytoskelettalen kontraktilen Proteins. Mehrere Mutationen im MYH-9-Gen führen zu Makrothrombozytopenie und zytoplasmischen Einschlusskörperchen in den Leukozyten, wobei die Anzahl der Leukozyten im Knochenmark normal bleibt. Vier überlappende Syndrome, die als May-HegglinAnomalie, Epstein-Syndrom, Fechtner-Syndrom und Sebastian-Platelet-Syndrom bekannt sind, beschreiben verschiedene klinische Manifestationen einer $\mathrm{MYH}-9$ Genmutation. Makrothrombozytopenie besteht bei allen betroffenen Personen. Die Syndrome unterscheiden sich hinsichtlich weiterer klinischer Manifestationen wie Nierenversagen, Hörverlust und präsenile Katarakte. Die Blutungstendenz ist meist moderat, wobei Menorrhagie und hohe Anfälligkeit für Blutergüsse die häufigsten Symptome sind. Das größte Risiko für die betroffenen Personen ist die unangemessene Behandlung aufgrund der Fehldiagnose "chronische Autoimmunthrombozytopenie". Mehr als 30 Mutationen innerhalb der 40 Exone des $\mathrm{MYH}$ 9-Gens, die zu Makrothrombozytopenie führen, sind bislang identifiziert, von denen die Upstream-Mutationen bis etwa zu Aminosäure 1400 mit einer höheren Wahrscheinlichkeit für syndromische Manifestationen assoziiert sind als die Downstream-Mutationen. Die Diagnose basiert auf der Identifizierung von Granulozyten-Einschlusskörperchen mit Hilfe von Blutausstrichen und Immunfluoreszenz und wird sicher bestätigt durch den Nachweis der Mutation. Die Behandlung ist unterstützend und zielt darauf, die Eisenmangelanämie zu vermeiden. Neben dem Nierenversagen ist das größte Risiko für Patienten, die von einer MYH-9-Erkrankung betroffen sind, die schädigenden Nebenwirkungen einer Behandlung, die auf der Fehldiagnose der Immunthrombozytopenie beruht.

\begin{tabular}{ll}
\hline KARGER & $\oplus$ 2010 S. Karger GmbH, Freiburg \\
Fax +497614520714 & Accessible online at: \\
Information@Karger.de & www.karger.com/tmh \\
www.karger.com &
\end{tabular}




\section{Introduction}

Several genetic mutations affect thrombopoiesis while megakaryocytopoiesis is only minimally disturbed. In these disorders typically megakaryocytes are present in the bone marrow in normal or even increased numbers, while platelet numbers are decreased and at the same time the platelet volume is increased, leading to macrothrombocytopenia. In other words, the same platelet mass is distributed into a smaller number of large platelets. Three mechanisms for formation of giant platelets are well characterized. They all affect the cascade involving: von Willebrand factor (von Willebrand disease type IIB), platelet glykoprotein (GP) IbIX complex (Bernard-Soulier syndrome), and the platelet cytoskeleton protein non-muscular myosin IIA (MYH-9 disorders). While Bernard-Soulier syndrome (BSS) is a recessive disorder, von Willebrand type IIB and MYH-9 related disorders are dominantly inherited.

MYH-9 related disorders are considered to be rare and only 113 unrelated families are reported in the literature. However, this might grossly underestimate the real prevalence. For example, in the region of Greifswald with a population of about 150,000 inhabitants we identified 5 unrelated families so far with giant platelets caused by $M Y H-9$ mutations. In our laboratory, giant platelet syndromes caused by dominantly inherited mutations in the $M Y H-9$ gene encoding the non-muscular myosin IIA are the most frequent of these disorders.

Non-muscular myosin IIA (NMM-IIA) is part of the myosin super family [1]. As a motality protein it is involved in cytokinesis, phagocytosis, cell motility and maintenance of cell shape. However, while in megakaryocytes and platelets only NMM-IIA is expressed, in eosinophilic granulocytes also NMM-IIB, is present, and many tissues also express NMMIIC in the embryonic stage. Although these other non-muscular myosin proteins can in part compensate for functional defects resulting form the mutated NMM-IIA protein, platelets only express the NMM-IIA. Furthermore NMM-IIA is also not ubiquitely co-expressed with the other NMMs. Therefore, mutations in the protein can also affect other organs beside the hematopoietic system, especially the inner ear, the eye lens and the podocytes in the kidneys. Four MYH-9 related syndromes can be distinguished by different combinations of clinical and laboratory signs, such as sensorineural hearing loss, cataract, nephritis and the presence of inclusion bodies in the leukocytes (table 1): May-Hegglin anomaly (MHA), Epstein syndrome (EPS), Fechtner syndrome (FTS), and Sebastian platelet syndrome (SPS).

First in 1909 May [2] found Döhle-like bodies in the neutrophils of several members of one family. In 1945, Hegglin [3] described a family with thrombocytopenia, giant platelets and leukocyte inclusions. This triad was later named MHA. Epstein described in 1972 [4] patients with macrothrombocytopenia, no visible inclusion bodies by light microscopy in the leukocytes, nephritis and sensorineural hearing loss. The FTS was first described by Peterson in 1985 [5] in a four-genera-
Table 1. Presence of thrombocytopenia and non-hematologic manifestations in MYH-9 related disorders

\begin{tabular}{lllll}
\hline & MHA & FTS & EPS & SPS \\
\hline Macrothrombocytopenia & + & + & + & + \\
Inclusion bodies large & + & - & - & - \\
Inclusion bodies small & - & + & - & + \\
Hearing loss & - & + & + & $(+)$ \\
Nephritis & - & + & + & - \\
Cataract & - & + & - & $(+)$ \\
\hline
\end{tabular}

$(+)=$ Manifestation of symptoms at older age.

tion family with macrothrombocytopenia, inclusion bodies in the leukocytes, sensorineural hearing loss, nephritis and cataract. Patients with SPS described in 1990 [6] present with macrothrombocytopenia and small inclusion bodies in leukocytes. From on the age of 50 affected individuals often develop cataract and increasing neurosensorial high tone hearing loss.

Mutations in the $M Y H-9$ gene encoding for NMM-IIA have been identified in all these syndromes [7-12].

Interestingly, mutations in the $M Y H-9$ gene do not always cause thrombocytopenia. An autosomal dominant form of non-syndromic sensorineural hearing loss (DFNA17) has also been associated with mutations in the $M Y H-9$ gene $[13,14]$. Furthermore certain SNPs in the $M Y H-9$ gene are strongly correlated to the risk for developing renal failure in hispanic Americans [15].

\section{Molecular Structure of the Non-Muscular Myosin IIA Protein}

NMM-IIA normally exists as a large hexamer, comprised of two heavy chains (NMMHC; MW $220 \mathrm{kDa}$ ) and 4 myosin light chains (MLC) (MW16.5 kDa), with a total molecular mass of $453 \mathrm{kDa}$. It has a N-terminal head (encoded by exons 1-18), a neck (exon 19) and a C-terminal tail (exons 20-40) [16-18]. The N-terminal head interacts with actin and exposes the ATP binding side. The neck includes the IQ motif, which is an important binding site for the MLCs. The MLC is responsible for inducing the acto-myosin contractile response. By phosphorylation of MLC, myosin becomes activated and can interact with actin filaments [19-22]. The C-terminal tail domain consists of two long alpha helices important for filament assembly and cargo binding [23]. These functionally different parts of the molecule give a first hint towards functional consequences of mutations. While mutations in the head region directly affect key functions of the motor protein, mutations in the tail region appear to have less critical effects on function (fig. 1). Mutated NMM-IIA forms aggregates in neutrophils [24, 25]. In these aggregates also non-mutated NMM-IIA which are transcribed from the normal allele are included. This causes further depletion of the protein and aggravates the clinical symptoms. 
Fig. 1. The upper part of the figure shows the schematic structure of the NMM-IIA protein. The middle part shows the genetic organization of the 40 exon gene, with exons 1-19 encoding for the head and neck part of the protein, while exons 20-40 encode for the tail part. Numbers of the exons in which mutations have been identified leading to MYH-9 disorders are highlighted. In the lower part of the figure the numbers of patients presenting with one of the clinical symptoms are given in relation to the total number of patients in whom we identified a mutation in a certain exon of the $M Y H-9$ gene [31] (? = insufficient data available).

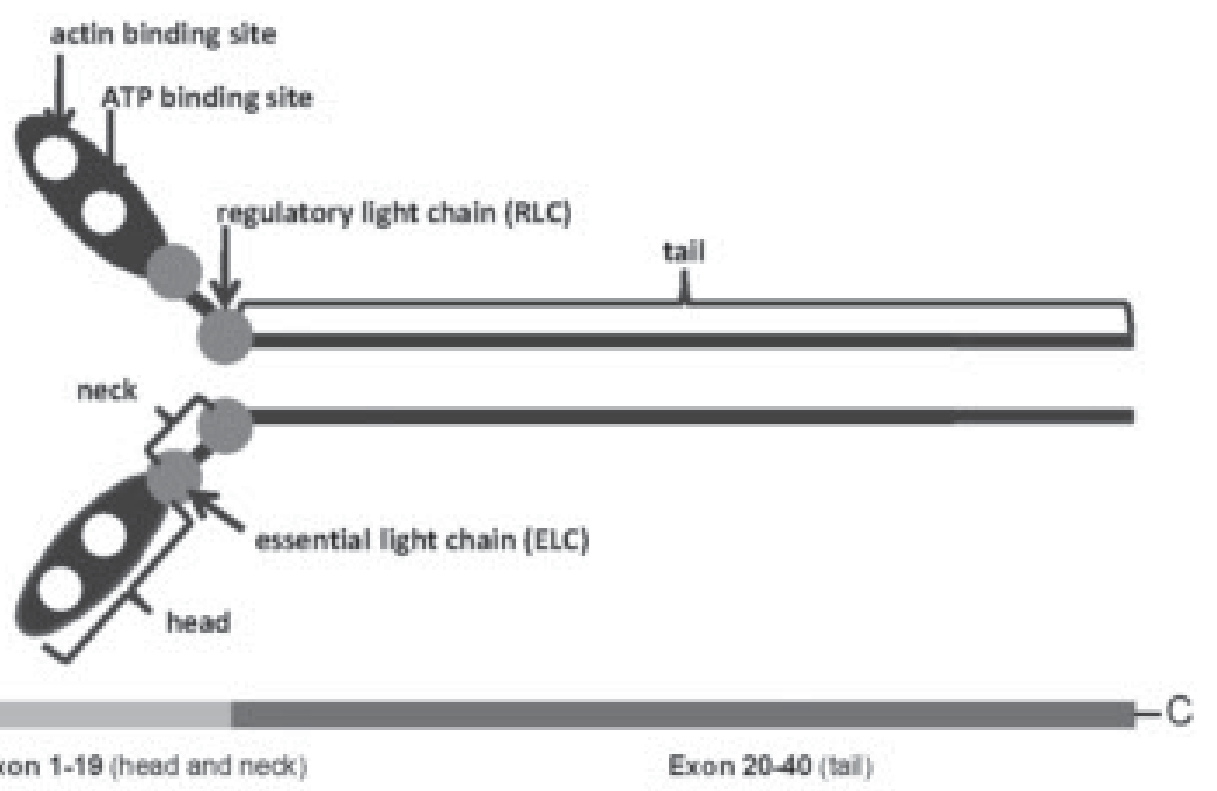

\begin{tabular}{|c|c|c|c|c|c|c|c|c|c|c|c|}
\hline exen & 1 & 10 & 16 & 24 & 25 & 26 & 10 & 31 & 37 & 38 & $\omega$ \\
\hline thrombocytopenta & $7 / 7$ & $1 / 1$ & $14 / 14$ & $1 / 1$ & $2 / 2$ & $14 / 14$ & $20 / 20$ & $1 / 1$ & $1 / 1$ & $20 / 20$ & $4 / 4$ \\
\hline hearing impaiment & $3 / 7$ & $o / 1$ & $13 / 14$ & $0 / 1$ & $0 / 2$ & $5 / 14$ & $11 / 20$ & $? / 1$ & $1 / 1$ & $0 / 20$ & $2 / 4$ \\
\hline renal impairment & $3 / 7$ & $0 / 1$ & $12 / 14$ & $a / 1$ & $1 / 2$ & $5 / 14$ & $6 / 20$ & $7 / 1$ & $1 / 1$ & $5 / 20$ & $2 / 4$ \\
\hline cataract & $a / 7$ & $a / 1$ & $5 / 14$ & $\omega /$ & $0 / 2$ & $3 / 14$ & $6 / 20$ & $2 / 1$ & $0 / 1$ & $1 / 20$ & $2 / 4$ \\
\hline
\end{tabular}

\section{Clinical Features of MYH-9 Giant Platelet Disorders}

In all individuals with a MYH-9 related platelet disorder, giant platelets are present from on birth. Platelet counts may vary between $<30,000 / \mu l$ and up to $100,000 / \mu l$, even between family members affected by the same $M Y H-9$ mutation. In the individual patient, however, the platelet count remains rather stable during life. This does not exclude a transient decrease in platelet count due to other acquired risk factors for thrombocytopenia, e.g. after viral infection. Easy bruising, epistaxis, and menorrhagia are the lead bleeding symptoms. Petechias are rare and do usually only occur if the platelet count further decreases due to comorbidities. In women, the leading problem is iron deficiency anemia caused by menorrhagia.

Figure 2 shows the pedigree of a family diagnosed in our laboratory with MHA, one of the syndromes of the MYH-9 related diseases, which is typically caused by mutations in one of the C-terminal exons (in this family the mutation was located in exon 38). Affected members of this family had a history of mild bleeding symptoms. Despite thrombocytopenia, family members I-I and II-II developed coronary artery disease and myocardial infarction requiring coronary artery bypass surgery at age 58 and 66, respectively. Despite thrombocytopenia, cardiac surgery was not associated with in- creased bleeding. However, neither of the patients received secondary prophylaxis with antiplatelet drugs due to fear of bleeding, and both developed recurrent myocardial infarction. Patient III-II presented during pregnancy with a history of easy bruising and bleeding after tooth extraction. Spontaneous delivery was performed without prophylactic platelet transfusion, and no bleeding complications occurred.

This family pedigree makes several important points: i) bleeding is usually not the leading problem in many of these patients; ii) in patients with a history of only minor bleeding, prophylactic platelet transfusion before major surgery is not necessary; iii) pregnancy is usually not complicated by major bleeding and spontaneous delivery seems to be appropriate (none of the affected individuals experienced intracerebral bleeding complications as newborns); iv) patients may develop arterial occlusions. Coronary artery disease is most likely not caused by the MYH-9 disease but by conventional risk factors of artherosclerosis. However, the secondary acute coronary syndrome might have been prevented by antiplatelet therapy, and patients with MYH-9 disease and acute coronary syndrome should receive secondary prophylaxis with antiplatelet drugs as MYH-9 related thrombocytopenia does not protect from myocardial infarction.

The non-hematological manifestations like high-tone sensorineural hearing loss, presenile manifestation of cataract 


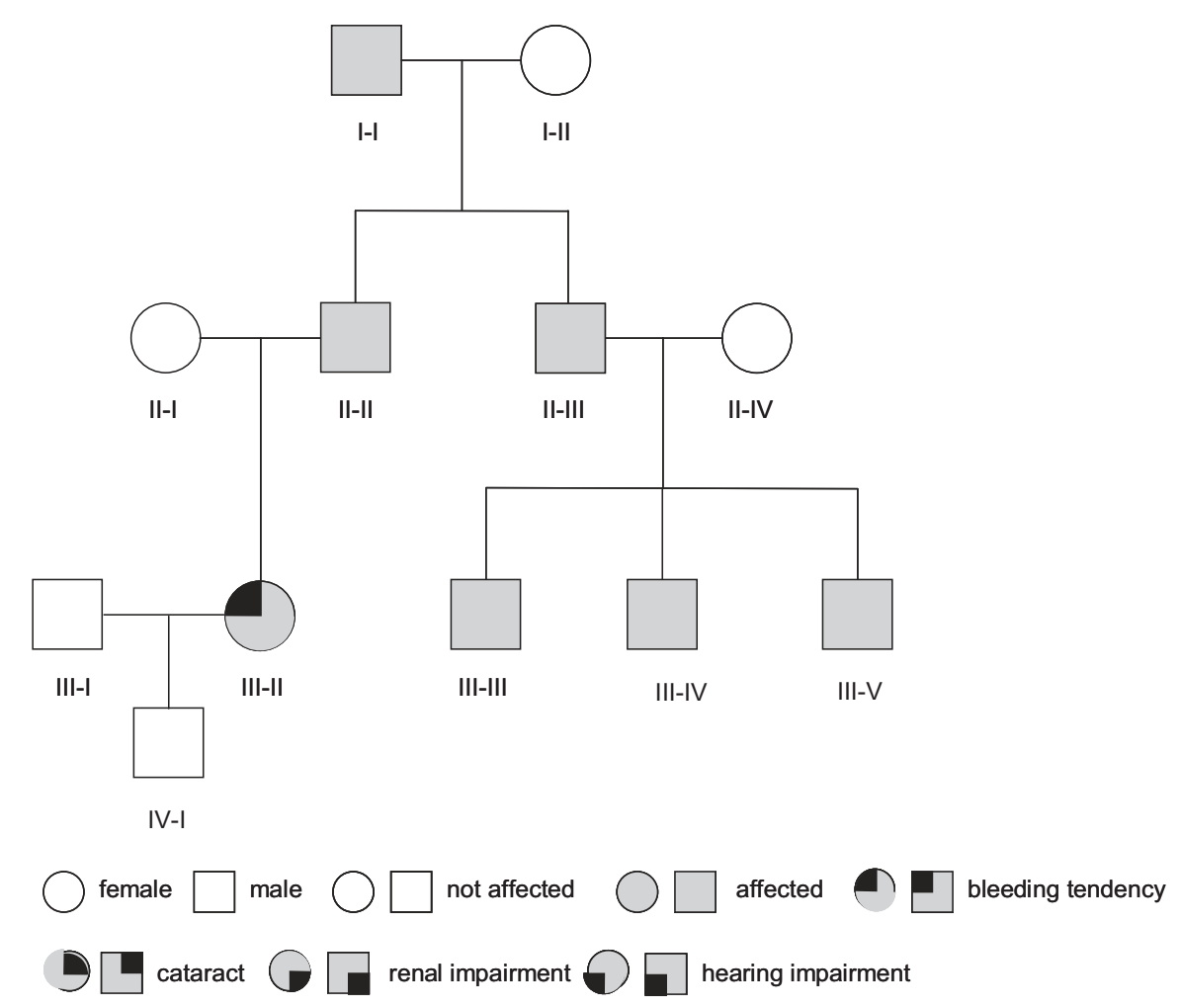

Fig. 2. Pedigree of a family with MHA, one of the MYH-9 related macrothrombocytopenias. In this family MHA is caused by a mutation in exon 38 of the $M Y H-9$ gene. Inclusion bodies in the leukocytes of these patients were large and spindle shaped (fig. 5a). Beside thrombocytopenia no non-hematologic manifestations were present in the family. Patient I-I and II-II had coronary artery disease. Antiplatelet therapy had been withhold due to the low platelet count and both patients developed several myocardial infarctions.

and glomerulonephritis can start to develop any time during life. Once hearing loss or proteinuria become detectable, they tend to progress. The risk for early onset of these complications differs between the syndromes. Patients with FTS have a high risk for renal disease and hearing loss beginning at adolescent age. In patients with SPS hearing loss and cataracts often develop from on the age of about 50 years, while patients with MHA often only present with thrombocytopenia. In most patients a presumption on the risk of manifestation of the non-hematological manifestations is possible based on the family history and location of the mutation [26].

\section{Diagnosis of MYH-9 Related Disease}

Identification of patients with probable MYH-9 related disorders is possible using basic hematologic investigation tools. Key parameters are blood cell count, mean platelet volume, and the platelet histogram, as well as platelet morphology in the blood smear. MYH-9 related disorders should be suspected in individuals with persistent low platelet counts, especially if [27]:

- the mean platelet volume is larger than $12 \mathrm{fl}$,

- the histogram shows a broad distribution of platelets instead of a semilogarithmic distribution and a peak preceding the leukocyte histogram (fig. 3),

- other family members also show thrombocytopenia (or easy bruising/menorrhagia),

- thrombocytopenia is non-responsive to corticosteroids,

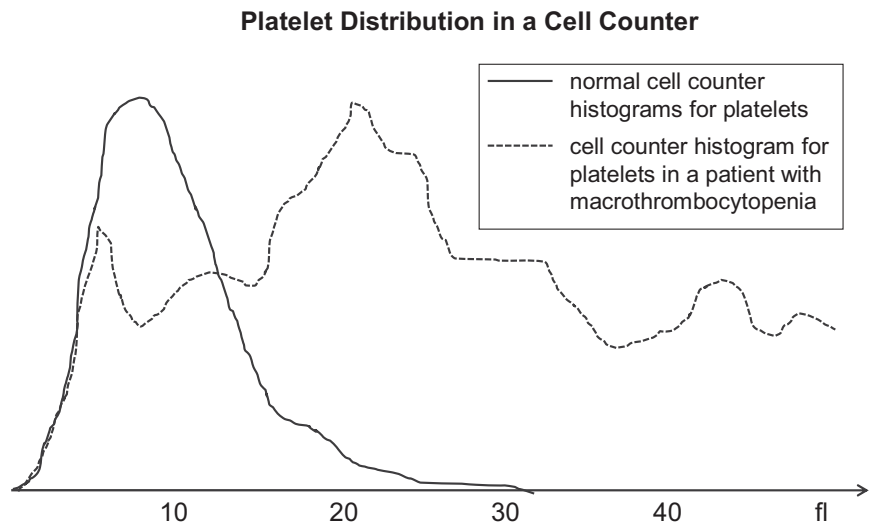

Fig. 3. Platelet histograms as obtained by routine laboratory particle counters for normal platelets (solid line) and typical broad distribution in patient with macrothrombocytopenia (dotted line).

- cataract, high tone hearing loss, or renal impairment is present in the patient or within the family.

A diagnostic flow chart to differentiate $\mathrm{MYH}-9$ related disorders from other macrothrombocytopenias is given in figure 4 .

There are several pitfalls in the diagnosis of MYH-9 related disorders. First, some automated particle counters largely underestimate the true platelet count number because the giant platelets are counted as erythrocytes or leukocytes dependent on the size restrictions of the machine. This is especially important if platelet counts are monitored after an intervention and different particle counters are used, one for routine presurgery analysis and another machine for monitor- 


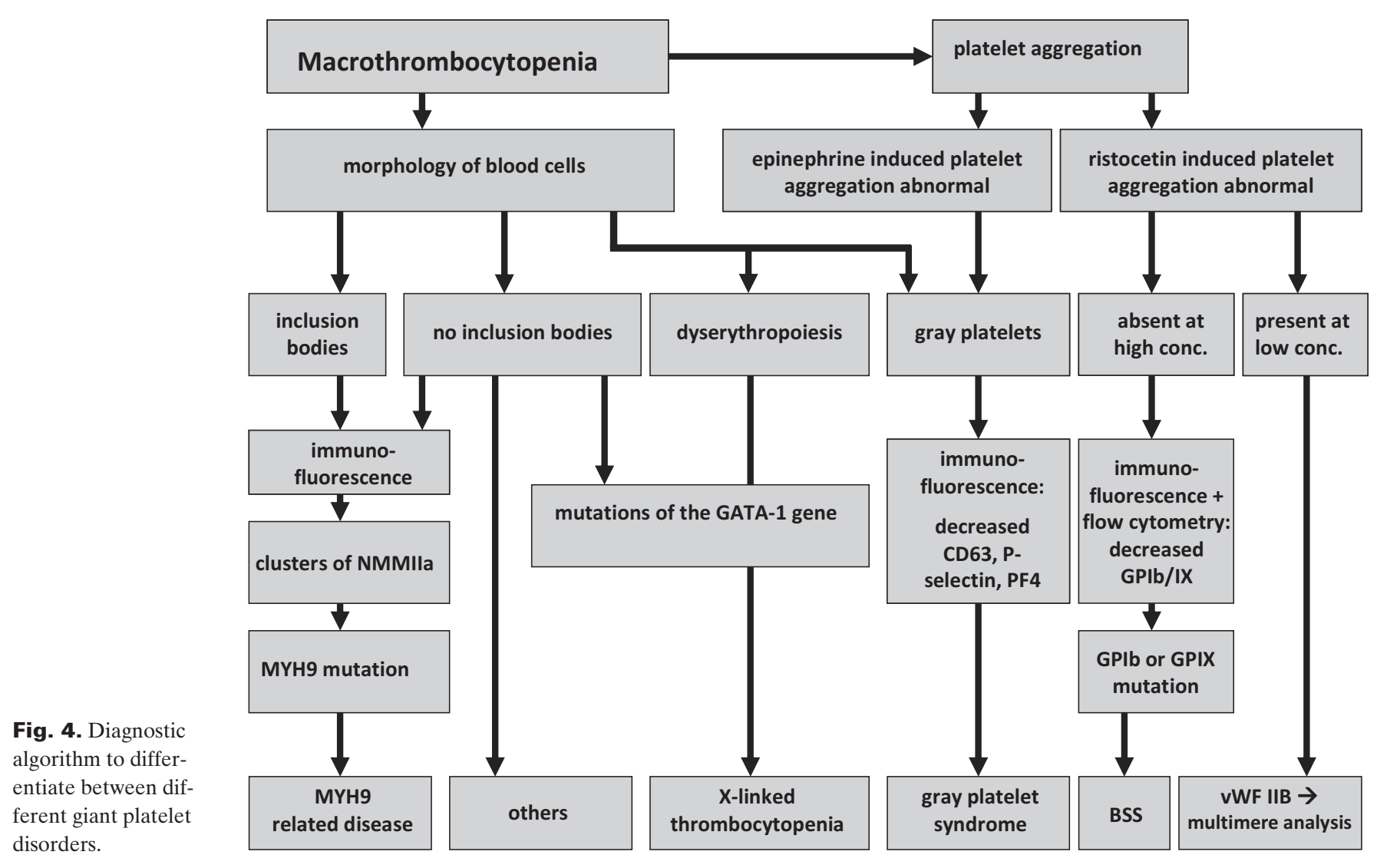

ing post surgery in the emergency laboratory. The point of care counters more likely underestimate the true platelet count, while the larger particle counters use additional parameters such a granularity to differentiate platelets from red blood cells.

Although MYH-9 disorders are dominantly inherited, a negative family history does not exclude MYH-9 related disease. The bleeding history alone might not reveal other affected family members as the bleeding tendency is usually mild. Therefore, platelet counts (not only the bleeding history) should be obtained in first-degree relatives. However, approximately $20-40 \%$ of affected individuals have a de novo mutation [28], and normal platelet counts in the parents do not exclude MYH-9 disorders.

In case of a more pronounced bleeding tendency, von Willebrand disease type IIB is more likely, and in case of consanguinity in the pedigree BSS should be considered. While dyserythropoiesis or manifestation in male family members only should prompt exclusion of a GATA-1 mutation (fig. 4).

\section{Diagnostic Approach in Specialized Laboratories: Blood} Smear - Immunofluorescence Microscopy - Genetic Analysis Careful analysis of the blood smear is still the most important screening tool. Inclusion bodies in the granulocytes appearing light blue by May-Grünwald-Giemsa staining strongly suggest a MYH-9 related disease. These blue inclusion bodies have a similar appearance as Döhle bodies found in severe infection. Depending on the location of the mutation, the size and also the stain of the inclusion bodies differ. Mutations in the Cterminal region of the protein usually cause large, spindleshaped inclusion bodies which stain strongly (fig. 5a). As further upstream the mutation is located, as smaller the NMMIIA clusters become (fig. 5b) and as less well they stain, especially if blood smears are stained more than $2 \mathrm{~h}$ after venipuncture and some mutations cause clusters of NMM-IIA which do not stain at all by May-Grünwald Giemsa stain (fig. 5c).

Immunofluorescence staining of NNM-IIA is much more sensitive and specific for NMM-IIA inclusion bodies in the granulocytes compared to standard stains [29, 30]. Figure 5 shows different examples of NMM-IIA clusters (oval-spindleshaped and oval-shaped) including an example of inclusion bodies in a granulocyte of a patient with EPS. These inclusion bodies are caused by a mutation at position S96L and are not visible by light microscopy.

Although this is still controversial in the literature, in our view there is a clear correlation between the location of the mutation in the $M Y H-9$ gene and the size and shape of the inclusion bodies. Neutrophils with one or two large oval-spindle-shaped inclusion bodies are typically present in individuals with mutations in exons 38 and 40. Smaller and round or slightly oval-shaped clusters are usually associated with muta- 


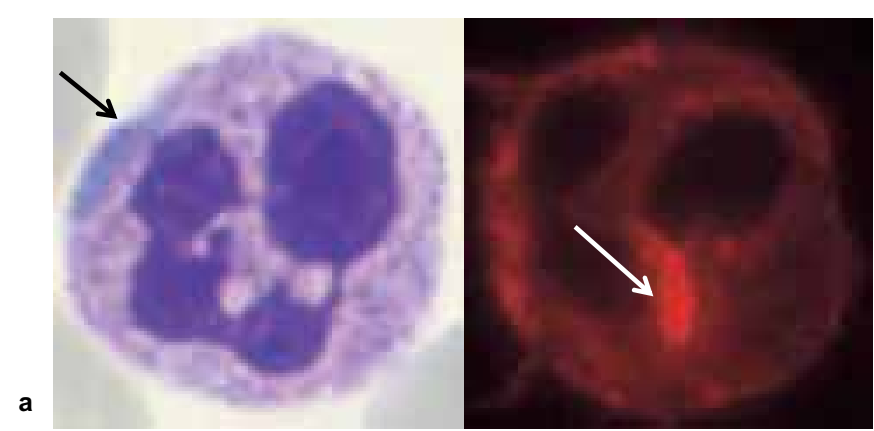

b
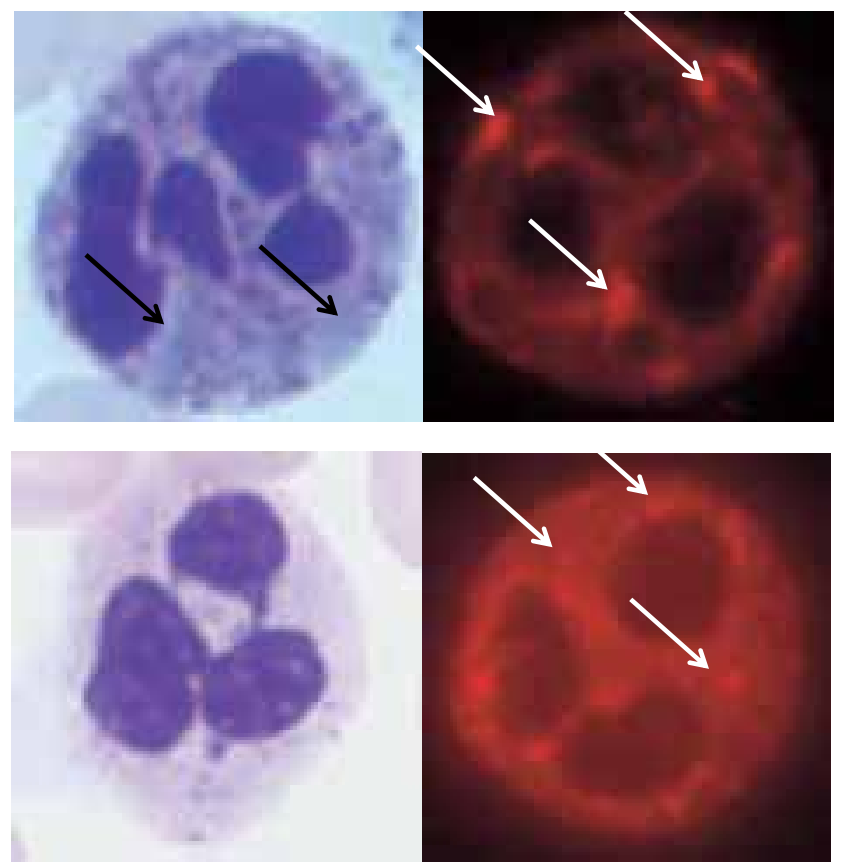

Fig. 5. Three different presentations of leukocyte inclusion bodies in MYH-9 related platelet disorders. The left part of the figure shows the inclusion bodies appearing in May-Grünwald-Giemsa stained blood smears, the right part shows immunofluorescence staining of NMM-IIA. a Presentation of inclusion bodies in a patient with a mutation in exon 38 (see also fig. 1). The large intensely stained spindle shaped cluster is clearly visible by light microscopy and is typical for the MHA. b Inclusion bodies caused by a mutation in exon 30 . The oval-shaped cytoplasmatic spots are difficult to spot by light microscopy but are clearly present after immuno staining. These inclusion bodies are often seen in patients with FTS or SPS. c Example of a mutation in exon 1 (S96L). These inclusion bodies do not show in the May-Grünwald-Giemsa stain and also require careful analysis of immunofluorescence staining. In such patients genetic testing is helpful to confirm the diagnosis of a MYH-9 disorder.

tions within exons 26-30 while speckled small punctate clusters are more often found in individuals with mutations in exon 1 and exon 16 [24, 31].

Genetic testing is not crucial for diagnosis of MYH-9 related disease. As the $M Y H-9$ gene consists of 40 exons, it is very elaborate to screen the entire gene. Genetic testing is helpful in patients with very small inclusion bodies and a noninformative family history to judge on the risk for developing renal insufficiency later in life. Patients with mutations in exon 16, especially affecting amino acid in position 702 and
705 , are at high risk and require regular monitoring of renal function (once per year). Again there is a controversy on whether a genotype-phenotype correlation exists in MYH-9 disorders. Our data indicate a higher risk for renal impairment, hearing loss and early onset cataract in patients with mutations in the head region as compared to patients with mutations in the tail region of the $M Y H-9$ gene [31].

Flow cytometry is primarily helpful to exclude BSS by assessment of GPIb and GPIX expression and is the only method to identify individuals being heterozygous for GPIb or GPIX mutations who can also present with some giant platelets and slightly reduced platelet counts and express only about $50 \%$ of GPIbIX complexes of the normal.

Assays measuring platelet associated IgG, either by ELISA or by flow cytometry, typically measure enhanced IgG binding to the giant platelets. This is caused by the larger platelet surface which results into higher unspecific binding of IgG and is not indicative for autoantibodies as a cause of thrombocytopenia. However, this artifact frequently leads to mistreatment of patients.

Platelet function studies show a reduced shape change in collagen induced platelet aggregation caused by the disturbed platelet cytoskeleton while the aggregation response is otherwise normal. In contrast, platelets from patients with BSS show absent aggregation with high concentrations of ristocetin, and platelets of patients with von Willebrand type IIB show increased aggregation at low concentrations of ristocetin. As this enhanced response is mediated by the von Willebrand factor, after plasma exchange normal platelets also show enhanced response to low concentrations of ristocetin.

\section{Management of Patients with MYH-9 Disorders}

Patients with $M Y H-9$ mutation related macrothrombocytopenia are often misdiagnosed as having immune thrombocytopenia, which then prompts ineffective and even potentially harmful treatments like intravenous IgG, immunosuppressive therapy and splenectomy. As the disease is dominantly inherited all first-degree relatives should be assessed for macrothrombocytopenia as the bleeding history alone is not sensitive enough. If the platelet count is normal, MYH-9 disease is excluded, and this individual person cannot pass the mutation. Usually, the history of older affected relatives provides an estimate of the risk to develop premature cataract, hearing loss and renal dysfunction. However, some individuals are more affected than others, even within the same family. We therefore recommend testing of renal function about once a year and performing a hearing test every 5 years.

Corticosteroids, intravenous $\mathrm{IgG}$, and splenectomy are ineffective in increasing platelet counts or reducing bleeding tendency in these patients. Patients with MYH-9 related disorders usually do not have life-threatening bleeding, and in general the recommendations for other bleeding disorders 
such as mild von Willebrand syndrome also apply for MYH-9 disorders. Patients should avoid any medications that impair platelet function, e.g. aspirin and other non-steroidal antiinflammatory drugs unless there is symptomatic arterial disease which mandates secondary prophylaxis. If these patients require a coronary stent, bare metal stents might be better suited than drug eluting stents, as they require a shorter duration of double antiplatelet therapy.

The most important preventive measure is to avoid iron deficiency anemia, especially in women at childbearing age. A low hematocrit will exacerbate the impaired platelet-subendothelial interactions (impaired primary hemostasis) even in patients with normal platelets [32]. Giant platelets tend to localize more into the middle of the blood flow and need the red blood cells to be shifted towards the vessel wall, thus enhancing their potential for subendothelial interaction [31] Hormonal contraceptives can reduce menorrhagia as well as tranexamic acid at a dose of $3 \times 1 \mathrm{~g}$ /day during the first 3 days of the menses. Desmopressin given as nose spray is little effective in MYH-9 related menorrhagia.

As inflamed and hyperemic gingival tissues are a risk factor for gum bleeding, regular dental care can help to avoid this additional cause of chronic blood loss.

Until now there is no known treatment to prevent the nonhematopoietic manifestations of NMM-IIA mutations. NMMIIA is important in stabilizing the cilia in the inner ear. Avoiding very loud noise at younger age might slow down the process of hearing loss, and cochlear implant should be an option to improve hearing in patients with deafness. In recent studies individuals with renal involvement had their proteinuria reduced by treatment with angiotensin receptor blockers and/or angiotensin-converting enzyme inhibitors [33]. In MYH-9 related disease pharmacological blockade of the renin-angiotensin system reduced proteinuria in 4 individuals [34]. This treatment should be offered to patients who show first symptoms of renal affection. However, it remains unclear whether this therapeutic approach prevents or delays the development of renal failure.

Pregnancy and childbirth do not appear to be associated with a major increase in bleeding complications in women with MYH-9 disorders. Furthermore, family histories suggest that spontaneous delivery do not put newborns with $\mathrm{MYH}-9$ mutation at increased risk for intracerebral hemorrhage. MYH-9 macrothrombocytopenia by itself does not mandate cesarean section. However, in case of prolonged labor, cesarean section might be less traumatic than other obstetrical interventions for affected children. If the mother or the father has an MYH-9 disorder, the platelet count of the newborn should be assessed directly after delivery, and in case of a low platelet count a cranial ultrasound should be performed to exclude intracranial hemorrhage which might require platelet transfusion.

We recommend all routine vaccinations, especially vaccinations for pertussis to avoid cough induced hemorrhage and for measles to prevent viral megakaryotoxicity. There are no data indicating that routine vaccination is associated with relevant intramuscular bleeding, but if the vaccine is approved for subcutanous application this route should be preferred.

Perisurgery major hemorrhage is rare in patients with MYH-9 disorders, and prophylactic platelet transfusions are not indicated even if the platelet count is low. We have managed individuals with MYH-9 disorders through a wide variety of surgical interventions, including dental extraction, tonsillectomy and adenectomy, cataract lens replacement, cesarean section, orthopedic joint replacement, cardiopulmonary bypass surgery as well as neurosurgical interventions. Our standard protocol is to give desmopressin $0.3 \mu \mathrm{g} / \mathrm{kg}$ body weight before surgery and $24 \mathrm{~h}$ later, and to combine this with tranexamic acid $0.5 \mathrm{~g}$ orally three times a day for 5 days after surgery (local application by mouth rinse after dental extraction). When the platelet counts of individuals with MYH-9 disorders are monitored, e.g. before and during interventions, it is important to use always the same counting machine as different machines show different error rates with giant platelets and a large unexpected decrease in platelet counts may simply result from using another machine.

While the literature does not report on increased bleeding after surgical interventions in MYH-9 disorders, we are aware of patient histories of major bleeding after tonsillectomy. Sehbai et al. [35] reported a neurosurgical intervention in an individual with MYH-9 with administration of desmopressin without bleeding complications. McBane et al. [36] reported hip arthroplasty in a patient with MYH-9 giant platelets without abnormal bleeding. At least 2 patients with MYH-9 related disorders are reported who developed thrombosis following surgery $[37,38]$. Therefore thrombosis prophylaxis should be given in situations with a high risk of thrombosis. This is especially important if also antifibrinolytic agents are given to prevent bleeding after surgery.

Very recently thrombopoietin receptor analogues have been approved (Romiplostim (Nplate ${ }^{\circledR}$ ) and eltrombopag $\left(\right.$ Revolade $^{\circledR}$, Promacta $\left.{ }^{\circledR}\right)$ ). We recommend to be very careful in applying these drugs to patients with $\mathrm{MYH}-9$ disorders. MYH- $9^{-/}$deficient stem cells differentiate into megakaryocytes that are fully capable of proplatelet formation, and thrombocytopenia in MYH-9 disorders results from ineffective platelet maturation due to the cytoskeletal abnormalities rather than from impaired megakaryopoiesis [39]. It is therefore likely that the thrombopoietin receptor agonists increase production of even larger platelets because the fragmentation defect is still present. These giant platelets are larger than the diameter of capillaries in the microcirculation and increasing the number of giant platelets may worsen the microcirculation because of the changed rheologic situation.

\section{Disclosure}

The authors have no conflict of interest to declare. 


\section{References}

1 Hodge T, Cope MJ: A myosin family tree. J Cell Sci 2000;113 Pt 19:3353-3354.

2 May R: Leukozyteneinschlüsse. Dtch Arc Klin Med 1909;96:1-6.

3 Hegglin R: Gleichzeitige konstituionelle Veränderungen an Neutrophilen und Thrombozyten. Helv Med Acta 1945;12:439-440.

$\checkmark 4$ Epstein CJ, Sahud MA, Piel CF: Hereditary macrothrombocytopathia, nephritis and deafness. Am J Med 1972;52:299-310.

$\checkmark 5$ Peterson LC, Rao KV, Crosson JT, White JG: Fechtner syndrome - a variant of Alport's syndrome with leukocyte inclusions and macrothrombocytopenia. Blood 1985;65:397-406.

6 Greinacher A, Nieuwenhuis HK, White JG: Sebastian platelet syndrome: a new variant of hereditary macrothrombocytopenia with leukocyte inclusions. Blut 1990;61:282-288.

7 Heath KE, Campos-Barros A, Toren A, Rozenfeld-Granot G, et al: Nonmuscle myosin heavy chain IIA mutations define a spectrum of autosomal dominant macrothrombocytopenias: MayHegglin anomaly and Fechtner, Sebastian, Epstein, and Alport-like syndromes. Am J Hum Genet 2001;69:1033-1045.

$>8$ Kelley MJ, Jawien W, Ortel TL, Korczak JF: Mutation of MYH9, encoding non-muscle myosin heavy chain A, in May-Hegglin anomaly. Nat Genet 2000;26:106-108.

$\checkmark 9$ Kunishima S, Kojima T, Matsushita T, Tanaka T, et al: Mutations in the NMMHC-A gene cause autosomal dominant macrothrombocytopenia with leukocyte inclusions (May-Hegglin anomaly/Sebastian syndrome). Blood 2001;97:1147-1149.

10 Martignetti JA, Heath KE, Harris J, Bizzaro N, et al: The gene for May-Hegglin anomaly localizes to $\mathrm{a}<1-\mathrm{Mb}$ region on chromosome 22q12.3-13.1. Am J Hum Genet 2000;66:1449-1454.

-11 Seri M, Cusano R, Gangarossa S, Caridi G, et al: Mutations in MYH9 result in the May-Hegglin anomaly, and Fechtner and Sebastian syndromes. The May-Heggllin/Fechtner Syndrome Consortium. Nat Genet 2000;26:103-105.

-12 Toren A, Rozenfeld-Granot G, Rocca B, Epstein CJ, et al: Autosomal-dominant giant platelet syndromes: a hint of the same genetic defect as in Fechtner syndrome owing to a similar genetic linkage to chromosome 22q11-13. Blood 2000;96:34473451.

13 Hildebrand MS, de Silva MG, Gardner RJ, Rose E, et al: Cochlear implants for DFNA17 deafness. Laryngoscope 2006;116:2211-2215.

14 Lalwani AK, Goldstein JA, Kelley MJ, Luxford W, et al: Human nonsyndromic hereditary deafness DFNA17 is due to a mutation in nonmuscle myosin MYH9. Am J Hum Genet 2000;67:1121-1128.
Behar DM, Rosset S, Tzur S, Selig S, et al: African ancestry allelic variation at the MYH9 gene contributes to increased susceptibility to non-diabetic end-stage kidney disease in Hispanic Americans. Hum Mol Genet 2010;19:1816-1827.

16 Marigo V, Nigro A, Pecci A, Montanaro D, et al: Correlation between the clinical phenotype of MYH9-related disease and tissue distribution of class II nonmuscle myosin heavy chains. Genomics 2004;83:1125-1133

17 Simons M, Wang M, McBride OW, Kawamoto S, et al: Human nonmuscle myosin heavy chains are encoded by two genes located on different chromosomes. Circ Res 1991;69:530-539.

18 Toothaker LE, Gonzalez DA, Tung N, Lemons RS, et al: Cellular myosin heavy chain in human leukocytes: isolation of 5 cDNA clones, characterization of the protein, chromosomal localization, and upregulation during myeloid differentiation. Blood 1991;78:1826-1833.

19 Fox JE, Phillips DR: Role of phosphorylation in mediating the association of myosin with the cytoskeletal structures of human platelets. J Biol Chem 1982;257:4120-4126.

20 Kumar CC, Mohan SR, Zavodny PJ, Narula SK, et al: Characterization and differential expression of human vascular smooth muscle myosin light chain 2 isoform in nonmuscle cells. Biochemistry 1989;28:4027-4035.

21 Paul BZ, Daniel JL, Kunapuli SP: Platelet shape change is mediated by both calcium-dependent and -independent signaling pathways. Role of p160 Rho-associated coiled-coil-containing protein kinase in platelet shape change. J Biol Chem 1999;274:28293-28300.

22 Suzuki Y, Yamamoto M, Wada H, Ito M, et al: Agonist-induced regulation of myosin phosphatase activity in human platelets through activation of Rho-kinase. Blood 1999;93:3408-3417.

23 Berg JS, Powell BC, Cheney RE: A millennial myosin census. Mol Biol Cell 2001;12:780-794.

24 Kunishima S, Matsushita T, Kojima T, Sako M, et al: Immunofluorescence analysis of neutrophil nonmuscle myosin heavy chain-A in MYH9 disorders: association of subcellular localization with MYH9 mutations. Lab Invest 2003;83:115-122.

25 Maupin P, Phillips CL, Adelstein RS, Pollard TD: Differential localization of myosin-II isozymes in human cultured cells and blood cells. J Cell Sci 1994; 107 Pt 11:3077-3090.

26 Pecci A, Panza E, Pujol-Moix N, Klersy C, et al: Position of nonmuscle myosin heavy chain IIA (NMMHC-IIA) mutations predicts the natural history of MYH9-related disease. Hum Mutat 2008; 29:409-417.
27 Noris P, Klersy C, Zecca M, Arcaini L, et al: Platelet size distinguishes between inherited macrothrombocytopenias and immune thrombocytopenia. J Thromb Haemost 2009;7:2131-2136.

28 Savoia A, Balduini A: MYH9-related disorders; in Pagon RA, Bird TC, Dolan CR, Stephens K (eds): GeneReviews [Internet]. Seattle: University of Washington, 1993-2008 Nov 20 [updated 2009 Jun 25].

29 Kunishima S, Matsushita T, Kojima T, Amemiya N, et al: Identification of six novel MYH9 mutations and genotype-phenotype relationships in autosomal dominant macrothrombocytopenia with leukocyte inclusions. J Hum Genet 2001;46:722-729.

30 Kunishima S, Hamaguchi M, Saito H: Differential expression of wild-type and mutant NMMHC-IIA polypeptides in blood cells suggests cell-specific regulation mechanisms in MYH9 disorders. Blood 2008;111:3015-3023.

-31 Althaus K, Greinacher A: MYH9-related platelet disorders. Semin Thromb Hemost 2009;35:189-203.

32 Eugster M, Reinhart WH: The influence of the haematocrit on primary haemostasis in vitro. Thromb Haemost 2005;94:1213-1218.

33 Nakao N, Yoshimura A, Morita H, Takada M, et al: Combination treatment of angiotensin-II receptor blocker and angiotensin-converting-enzyme inhibitor in non-diabetic renal disease (COOPERATE): a randomised controlled trial. Lancet 2003; 361:117-124.

34 Pecci A, Granata A, Fiore CE, Balduini CL: Reninangiotensin system blockade is effective in reducing proteinuria of patients with progressive nephropathy caused by MYH9 mutations (Fechtner-Epstein syndrome). Nephrol Dial Transplant 2008;23: 2690-2692.

35 Sehbai AS, Abraham J, Brown VK: Perioperative management of a patient with May-Hegglin anomaly requiring craniotomy. Am J Hematol 2005;79: 303-308.

36 McBane RD, Elliott MA, White JG, Charlesworth JE, Costopoulos MG, Owen WG, Nichols WL: Fechtner syndrome: physiologic analysis of macrothrombocytopenia. Blood Coagul Fibrinolysis 2000;11:243-247.

37 Heller PG, Pecci A, Glembotsky AC, Savoia A, et al: Unexplained recurrent venous thrombosis in a patient with MYH9-related disease. Platelets 2006;17:274-275.

38 Selleng K, Lubenow LE, Greinacher A, Warkentin TE: Perioperative management of MYH9 hereditary macrothrombocytopenia (Fechtner syndrome). Eur J Haematol 2007;79:263-268.

39 Chen Z, Naveiras O, Balduini A, Mammoto A, et al: The May-Hegglin anomaly gene MYH9 is a negative regulator of platelet biogenesis modulated by the Rho-ROCK pathway. Blood 2007;110:171-179. 